\title{
Asthma education by community child health nurses
}

\author{
E A MITCHELL, V FERGUSON, AND M NORWOOD
}

Department of Health, South Auckland Health District, Manukau City, Auckland, New Zealand

SUMMARY A randomised controlled study of an educational programme for children with asthma and their families was carried out by community child health nurses. Three hundred and sixty eight children aged 2 to 14 years were enrolled in the study after admission to hospital for asthma. The intervention group was visited monthly by a nurse for six months. The subjects were assessed six months later by a postal, self administered questionnaire. European children in the intervention group were taking significantly more drugs for the treatment of asthma six months after the index admission to hospital than those in the control group (mean (SD) intake $2 \cdot 7(1 \cdot 1)$ $v 2 \cdot 1(1 \cdot 0)$, respectively). In particular, they were using more theophylline $(56 \cdot 6 \% v 37 \cdot 0 \%)$ and inhaled steroids $(34.9 \% \vee 21.0 \%)$. There was no difference between the groups for parental reports of improvement, of missed schooling, and in severe attacks of asthma of not responding to the usual treatment at home. European children in the intervention group used the hospital services for severe attacks of asthma more than controls $(34.2 \% v 10 \cdot 5 \%)$. There were more readmissions in the European intervention group in the subsequent six months after the index admission than in the control group (mean (SD) $0.51(0.97) v 0.29(0.65)$ ). Re-admission continued to be higher in the 12 months after the nurse had stopped visiting $(0 \cdot 81(1.65) v 0.258$ $(0 \cdot 65))$. There was no difference in the duration of hospital stay between the intervention and control groups. For Polynesian children there was no difference between the groups for any outcome measures.

Rates of admission to hospital for asthma in the $0-14$ year age group have increased strikingly since the mid-1960s in New Zealand, the United States, Canada, England and Wales, and Australia. ${ }^{1}$ Part of this increase is due to an increase in the re-admission rate. $^{2-4}$ In New Zealand both admission and readmission rates are higher in Polynesian than in European children. ${ }^{45}$

An earlier study in Auckland showed that, compared with Europeans, Polynesians were using less drugs for asthma, particularly those used for prophylaxis, were more likely to run out of medication, and were referred to hospital more often by the accident and emergency department and less often by their general practitioner. ${ }^{5}$ In England there has been a shift in the care of patients with asthma from primary care towards the hospital and also an increase in the number of self referred patients. ${ }^{23}$ These patients tended to have less severe asthma on admission than patients referred by their general practitioner.

Asthma is underdiagnosed and undertreated, ${ }^{6}$ and many paediatric admissions to hospital for asthma are, in some way, related to improper action taken by the patient, his family, or the health care professional. ${ }^{78} \mathrm{~A}$ recently reported intensive programme designed to teach self management skills to 13 children with asthma and their parents by a specially trained nurse educator resulted in fewer admissions to hospital and emergency room visits compared with 13 control patients, less school absenteeism, and fewer attacks of asthma. ${ }^{9}$ Although this programme has been shown to be effective, it would be expensive to implement for all patients with asthma.

The purpose of this study was to determine whether additional education of children with asthma and their parents by community child health nurses* in the patients' homes could alter the course of their disease. The specific aims of the study were to reduce school absenteeism, to encourage visits to their general practitioner, to reduce the number of re-admissions to hospital and to teach parents and the child when to start additional treatment and when to seek medical help for the attack of asthma not responding to the usual treatment.

${ }^{*}$ Strictly speaking, the nurses were public health nurses employed by the Department of Health. 


\section{Patients and methods}

Patients discharged from the paediatric medical wards of Auckland Hospital for asthma (ICD 493) over a one year period (from 15 April 1983 to 14 April 1984) were entered into the study. Patients aged less than 2 years and patients whose home was outside the hospital catchment area were excluded. A small number of patients with asthma who had had previous life threatening attacks were also excluded. All parents of the subjects completed a questionnaire on admission, which was based on previously published questionnaires concerning the child's medical history and social characteristics of the family. ${ }^{10} 11$

Patients were divided into two ethnic groups, (1) Polynesians, which included Maoris and Polynesian Pacific Islanders, and (2) Europeans, because there are considerable differences in the medical management of their asthma, rates of re-admission, and socioeconomic state. ${ }^{45}$ Other ethnic groups were excluded. They were then randomised into an intervention or control group at the time of discharge from hospital. The patients and their families in the intervention group were visited monthly by a community child health nurse for six months. The intervention programme performed by the child health nurse was as follows.

(a) An explanation of the anatomy, pulmonary physiology, and pathophysiology of the lung and of the factors that can provoke asthmafor example, allergies, infections, exercise, and emotions.

(b) A description of the drugs used in asthma, especially those drugs prescribed for the child.

(c) Emphasis of the importance of avoiding stimuli that may provoke asthma and controlling the patient's environment-for example, measures to avoid home dust.

(d) A check on drug compliance (inspection of the contents of bottles of medicine to ensure drugs do not run out) and correct use of aerosols.

(e) Encouragement to attend follow up clinic visits to either the paediatrician at the paediatric outpatient clinic, if arranged, or to their general practitioner.

(f) Encouragement to consult their general practitioner rather than the accident and emergency department in the event of an attack of asthma not responding to treatment with bronchodilator at home.

No attempt was made to influence the type of treatment given to the child or the type of follow up received. The nurses contacted the child's general practitioner, however, to inform him of their involvement and to obtain up to date information on the patient and his family. The nurses were asked to keep a record of the number of patient/family contacts but were not asked to collect any other data.

Six months after discharge from hospital the child's progress and current management and family attitudes to their child's asthma and its management were examined, using a postal, self administered questionnaire. If a reply was not received a further copy of the questionnaire was sent. There were no further attempts after this to contact the family. In addition, the number of re-admissions and the duration of each re-admission to hospital for the six months after the index admission when the child health nurse was visiting and for the 12 months after the nurse had stopped visiting (six to 18 months after the index admission) were extracted from the hospital records. The last patient completed the 18 months' follow up on 14 October 1985.

Results are expressed as mean (SD) and were analysed using standard parametric and nonparametric tests of significance.

The study was approved by the Auckland Hospital ethical committee.

\section{Results}

Three hundred and sixty eight patients were entered into the study, of whom 200 were European and 168 Polynesian. There were 94 European children in the intervention group and 106 in the control group and 84 Polynesian children in both the intervention and control groups.

The age and sex ratio of European children $(6 \cdot 1(3.4)$ years, male:female ratio $1 \cdot 4: 1)$ did not differ from that of Polynesian children (5.5 (3.0) years, 1·6:1). European children were significantly socioeconomically advantaged compared with Polynesians, as measured by the occupations of the parents, home ownership, and having their own bedrooms. On admission to hospital European children were taking a larger number of medications for asthma than Polynesians $(1.8(1.2) v 1.4(1.3)$, respectively, $\mathrm{p}<0 \cdot 001)$, and were significantly more likely to be taking cromoglycate, inhaled steroids, and sympathomimetics.

The child health nurses returned visit numbers on 135 intervention patients $(76 \%)$. Of the returns, eight $(6 \%)$ had no visits as the families could not be located, $35(26 \%)$ had some but not all six of the monthly visits, and $92(68 \%)$ had all six of the monthly visits.

Parents of the European children in the intervention group were more likely to return the second 
questionnaire than parents in the control group $(88 \% \vee 76 \%$, respectively, $\mathrm{p}=0.029)$. The respective percentage returns for Polynesians were $60 \%$ and $54 \%$ (not significant).

Tables 1 and 2 summarise the results of the intervention for the European and Polynesian children, respectively. European children in the intervention group were taking significantly more drugs for the treatment of asthma six months after the index admission to hospital than those in the control group $(2.7(1.1) \vee 2.1(1.0)$, respectively, $\mathrm{p}<0.001)$. In particular, they were taking more theophylline $(57 \% v 37 \%, \mathrm{p}=0.012)$ and inhaled steroids $(35 \% \vee 21 \%, p=0 \cdot 047)$. There was no difference between the groups for parental reports of improvement, of missed schooling, and in severe attacks of asthma of not responding to the usual treatment at home. If the child had an attack of asthma not responding to usual treatment they were more likely to be taken to a general practitioner rather than the hospital (including the accident and emergency departments or directly to the children's wards), but the intervention group used the hospital service for primary care more often than the control group $(34 \% v 11 \%, \mathrm{p}=0.043)$. There were more readmissions in the European intervention group in the subsequent six months after the index admission than in the control group $(0.51(0.97) v 0.29(0.65)$, $p=0.067)$, although the number of patients readmitted in the intervention group did not significantly differ from the control group (30\% v $21 \%)$. In the next 12 months, six to 18 months after the index admission, more patients were re-admitted from the intervention group than from the control group $(32 \% v 16 \%, \mathrm{p}=0.008)$ and the number of readmissions was also greater $(0.81(1.65) \quad v \quad 0.25$

Table 1 Progress at six and 18 months after index admission to hospital for European children with asthma. Values are No $(\%)$ unless otherwise stated

\begin{tabular}{|c|c|c|c|}
\hline & \multicolumn{2}{|c|}{ Treatment group } & \multirow[b]{2}{*}{ p Value } \\
\hline & Intervention & Control & \\
\hline Six months after index admission & $(n=83)$ & $(\mathrm{n}=81)$ & \\
\hline \multicolumn{4}{|l|}{ Current asthma drug treatment: } \\
\hline Nil & $0(0)$ & $6(7)$ & 0.012 \\
\hline Mean (SD) No & $2 \cdot 7(1 \cdot 1)$ & $2 \cdot 1(1 \cdot(0)$ & $0 \cdot(0) 1$ \\
\hline \multicolumn{4}{|l|}{ Sympathomimetics: } \\
\hline Regular & $42(51)$ & $33(41)$ & NS \\
\hline As required & $58(70)$ & $49(61)$ & NS \\
\hline Total & $76(92)$ & $69(85)$ & NS \\
\hline \multicolumn{4}{|l|}{ Theophylline: } \\
\hline Regular & $23(28)$ & $14(17)$ & NS \\
\hline As required & $25(30)$ & $16(20)$ & NS \\
\hline Total & 47 (57) & $30(37)$ & $0 \cdot(012$ \\
\hline \multicolumn{4}{|l|}{ Cromoglycate: } \\
\hline Regular & $36(4.3)$ & $31(38)$ & NS \\
\hline As required & $2(2)$ & $4(5)$ & NS \\
\hline \multicolumn{4}{|l|}{ Oral steroids: } \\
\hline Regular & $3(4)$ & $0(0)$ & NS \\
\hline As required & $2(2)$ & $3(4)$ & NS \\
\hline \multicolumn{4}{|l|}{ Inhaled steroids: } \\
\hline Regular & $29(35)$ & $17(21)$ & $0 .(047$ \\
\hline As required & 1 (1) & $2(3)$ & NS \\
\hline Other (ipratropium, antibiotics, cough mixture. antihistamines) & 10) (12) & $5(6)$ & NS \\
\hline Improved $(\%)$ & 80 & 76 & NS \\
\hline Asthma attack not responding to usual treatment at home $(\%)$ & 48 & 46 & NS \\
\hline \multicolumn{4}{|l|}{ Where this attack was treated $(\%)$ : } \\
\hline General practice & 61 & 84 & \\
\hline Hospital & 34 & 11 & \\
\hline Other & 5 & 5 & $0 .(04.3$ \\
\hline Mean (SD) days off school in previous six months & $8 \cdot 6(15 \cdot 1)$ & $6 \cdot 3(8 \cdot 8)$ & NS \\
\hline Child knows how to prevent an attack of asthma $(\%)$ & 30 & 37 & NS \\
\hline Parent knows when to start additional treatment $(\%)$ & 96 & 98 & NS \\
\hline Parent knows when to seek further medical advice (\%) & 98 & 99 & NS \\
\hline Re-admissions in six months after index admission & $(n=94)$ & $(n=106)$ & \\
\hline$\%$ Of patients & 30 & 21 & NS \\
\hline Mean (SD) of re-admissions & $(0.51 \quad(0.97)$ & $0.29(0.65)$ & 0.067 \\
\hline Mean (SD) duration of hospital stay (days) & $4 \cdot 0(7 \cdot 7)$ & $2.5(1.5)$ & NS \\
\hline Re-admissions between six and 18 months after index admission & $(n=94)$ & $(n=106)$ & \\
\hline$\%$ Of patients & 32 & 16 & 0.008 \\
\hline Mean (SD) of re-admissions & $(1.81 \quad(1.65)$ & $0.25(0.65)$ & 0.1003 \\
\hline Mean (SD) duration of hospital stay (days) & $3.1(2 \cdot 4)$ & $3 \cdot 1(2 \cdot 4)$ & NS \\
\hline
\end{tabular}

NS $=$ Not significant 
Table 2 Progress at six and 18 months after index admission to hospital for Polynesian children with asthma. Values are No (\%) unless otherwise stated

\begin{tabular}{|c|c|c|c|}
\hline & \multicolumn{2}{|c|}{ Treatment group } & \multirow[b]{2}{*}{$p$ Value } \\
\hline & Intervention & Control & \\
\hline \multirow{2}{*}{\multicolumn{4}{|c|}{ Current asthma drug treatment: }} \\
\hline & & & \\
\hline Nil & $3(6)$ & $5(11)$ & NS \\
\hline Mean (SD) No & $2 \cdot 0(1 \cdot 16)$ & $1.98(1.96)$ & NS \\
\hline \multicolumn{4}{|l|}{ Sympathomimetics: } \\
\hline Regular & $25(50)$ & $14(31)$ & NS \\
\hline As required & $20(40)$ & $28(62)$ & 0.031 \\
\hline Total & $40(80)$ & $34(76)$ & NS \\
\hline \multicolumn{4}{|l|}{ Theophylline: } \\
\hline Regular & $14(28)$ & $9(20)$ & NS \\
\hline As required & $9(18)$ & $11(24)$ & NS \\
\hline Total & $23(46)$ & $19(42)$ & NS \\
\hline \multicolumn{4}{|l|}{ Cromoglycate: } \\
\hline Regular & $15(30)$ & $10(22)$ & NS \\
\hline As required & $3(6)$ & $1(2)$ & NS \\
\hline \multicolumn{4}{|l|}{ Oral steroids: } \\
\hline Regular & $0(0)$ & $0(0)$ & NS \\
\hline As required & 1 (2) & 1 (2) & NS \\
\hline \multicolumn{4}{|l|}{ Inhaled steroids: } \\
\hline Regular & $11(22)$ & $11(24)$ & NS \\
\hline As required & $0(0)$ & $1(2)$ & NS \\
\hline Other (ipratropium, antibiotics, cough mixture, antihistamines) & $3(6)$ & $4(9)$ & \\
\hline Improved (\%) & 86 & 82 & NS \\
\hline \multirow{2}{*}{\multicolumn{4}{|c|}{ Where this attack was treated $(\%)$ : }} \\
\hline & & & \\
\hline General practice & 47 & 65 & \\
\hline Hospital & 47 & 30 & \\
\hline Other & 7 & 4 & NS \\
\hline Mean (SD) days off school in previous six months & $6 \cdot 8(6 \cdot 6)$ & $12 \cdot 4(25 \cdot 2)$ & NS \\
\hline Child knows how to prevent an attack of asthma (\%) & 39 & 24 & NS \\
\hline Parent knows when to start additional treatment $(\%)$ & 96 & 98 & NS \\
\hline Parent knows when to seek further medical advice (\%) & 95 & 98 & NS \\
\hline Re-admissions in six months after index admission & $(\mathrm{n}=84)$ & $(\mathrm{n}=84)$ & \\
\hline$\%$ Of patients & & & NS \\
\hline Mean (SD) of re-admissions & $0.48(0.83)$ & $0.38(0.71)$ & NS \\
\hline Mean (SD) duration of hospital stay (days) & $2 \cdot 7(1.4)$ & $3.5(2 \cdot 6)$ & NS \\
\hline Re-admissions between six and 18 months after index admission & $(n=84)$ & $(n=84)$ & \\
\hline$\%$ Of patients & 32 & 33 & NS \\
\hline Mean (SD) of re-admissions & $0.69(1.34)$ & $0.57(1 \cdot 10)$ & NS \\
\hline Mean (SD) duration of hospital stay (days) & $4.3(3.9)$ & $3 \cdot 3(2 \cdot 1)$ & NS \\
\hline
\end{tabular}

NS=Not significant.

$(0 \cdot 65), p=0.003)$, but there was no difference in the duration of hospital stay. There were no deaths in either group.

For Polynesian children there was no difference between the intervention and control groups for any of the outcome measures made six months after the index admission. Also there was no difference between the groups in re-admissions or duration of hospital stay six to 18 months after the index admission. Again there were no deaths in either group.

\section{Discussion}

Asthma is one of the most common diseases in childhood. Estimates of the prevalence of asthma in New Zealand have yielded results ranging from $1.9 \%{ }^{12}$ to $25 \%,{ }^{13}$ and this seems to be increasing. ${ }^{14}$ This difference almost certainly reflects differences in the classification of asthma and wheeze. Although death is rare in childhood, ${ }^{15}$ it is an important cause of admission to hospital ${ }^{\prime}$ and morbidity. ${ }^{6}{ }^{16} \mathrm{Com}$ munity studies show that asthma is underdiagnosed and undertreated ${ }^{6}{ }^{17}$ and that children with asthma are also often absent from school because of ill health. ${ }^{13} 18$

In this study the children were having frequent attacks of asthma (an average of 13 each year, lasting on average two days), were missing an average of three and a half weeks of school because of asthma, and by the completion of the study had had an average of 5.3 admissions to hospital for asthma.

In New Zealand in 1983 there were 5240 admissions in the 0-14 year age group, a rate of 634 per 100000 population. ${ }^{19} \mathrm{Re}$-admissions for asthma are common $^{3-58}$ and are increasing. ${ }^{34}$ Rate of readmission are higher in Polynesian than European 
children. ${ }^{4}$ This study confirms this finding; $49 \%$ of European children were first admissions for asthma compared with only $31 \%$ of Polynesian children. A reduction in the rates of re-admission would markedly reduce the total number of admissions to hospital for asthma.

Teaching self management skills to children with asthma and their parents by a specially trained nurse educator is effective in reducing admissions to hospital for and morbidity from asthma. ${ }^{9}$ Providing such a service for all children with asthma, however, would be prohibitively expensive. Accordingly we used the existing community nursing servicesnamely, public health nurses employed by the Department of Health. An important aspect of their role is the continuing care of children in schools and the community. The nurses were given additional training on asthma by one of us (EAM).

The study would have been more powerful if we could have included a wider range of outcome measures. Ideally, daily asthma diaries and measurements of peak expiratory flow would have been used; they could not be included in the control group, however, without possibly having some beneficial effect of their own. The outcome variables therefore chosen were hard data, such as re-admissions, missed schooling, and parental reports of the medical management of their child's asthma and their perception of their own and their child's management skills.

The study found that European children in the intervention group were taking significantly more drugs for asthma six months after the index admission to hospital than in the control group. More were taking medications for asthma in each drug category (with preventative drugs, theophylline, and inhaled steroids reaching significance). This result probably represents improved compliance. This increased use of medications, however, was not associated with an increased parental report of improvement, a reduction of missed schooling, or a reduction in attacks of asthma not responding to the usual treatment at home. The nurses were asked to encourage the families to use their general practitioner rather than the accident and emergency departments for severe attacks of asthma. The result of the intervention was the converse of this, with $34 \%$ in the intervention group using the hospital services when they had a severe attack compared with only $11 \%$ in the control group $(p=0 \cdot 043)$. A possible explanation for this unexpected finding was that the nurses taught the children and their parents to take attacks of asthma seriously, to seek medical help early, and if their general practitioner was not readily available to go directly to hospital for treatment of the attack of asthma not responding to the usual treatment. The parents' perception of their knowledge of when to begin additional treatment for asthma and when to seek further medical advice was uniformally high in both the intervention and control groups and did not differ statistically. The result that was unexpected and of most concern was that re-admissions in the next six months, when the nurse was visiting, and between six and 18 months after the index admission were greater in the intervention group than in the control group. Although this was the opposite to our original aim, it could be argued that this was beneficial and that this high risk group of patients were making more effective use of the available facilities. ${ }^{20}$ These admissions to hospital did not result, however, in a shorter duration of stay.

Polynesians have higher mortality ${ }^{12}$ and rates of admission to hospital for asthma. ${ }^{4}$ They also tend to have poorer health than Europeans on a number of health indices. ${ }^{21}$ It is well known that Polynesians make poor use of the available health services, which has many similarities to the National Health Service in the United Kingdom. As less than $60 \%$ of the Polynesian parents returned the postal questionnaire six months after the index admission the results of the intervention have to be interpreted with caution. We were unable to show, however, that intervention influenced any of the outcome variables. In contrast to the European subjects, there was no effect on re-admissions in the intervention group.

Other recently reported evaluations of programmes of patient education for children with asthma and their parents suggest that these programmes can reduce school absenteeism, emergency room visits, and admissions to hospital and improve activity. ${ }^{22}{ }^{23}$ The subjects from these other trials were enrolled from clinics ${ }^{923}$ or in response to media advertisements. ${ }^{22}$ Our subjects were enrolled at the time of the admission to hospital and in comparison to the subjects in these other studies had more severe asthma. Admission to hospital is almost certainly a major intervention in itself as all children admitted with asthma are seen by a paediatrician and treatment is rationalised, inhaler technique checked, compliance assessed, and a crisis plan devised. This major educational opportunity occurred for all patients in both the intervention and control groups and many have diminished the beneficial effect of the educational programme carried out by the child health nurse.

These results were discussed with the nurses involved in the study. A valid criticism was that the outcome measures did not cover areas where they thought they had produced the greatest improvement, such as the child's activity and well being, 
parental knowledge, and ability in handling an asthmatic crisis.

Less than $5 \%$ of children were taking systemic prednisone before admission to hospital. Although this study did not attempt to influence the type of treatment given to the child, the use of short courses of oral steroids begun by the parents may have prevented some of the original admissions to hospital and subsequent re-admissions. This is worthy of future study.

The study indicates that it is possible to improve compliance with treatment for asthma by using nurse educators, but improved compliance and education in themselves may not necessarily reduce admission to hospital and school absenteeism in the high risk child with asthma. Further educational programmes need to be developed and the delivery of culturally relevant health care to Polynesians improved.

We thank the public health nurses of the Takapuna, Auckland, and South Auckland Health Districts for carrying out the intervention programme and the paediatricians of Auckland Hospital for allowing us to study their patients. We also thank Mr P Flynn for additional statistical analysis. Permission to publish from the Director-General of Health is acknowledged.

\section{References}

1 Mitchell EA. International trends in hospital admission rates for asthma. Arch Dis Child 1985;60:376-8.

2 Anderson HR. Increase in hospitalisation for childhood asthma. Arch Dis Child 1978;53:295-300.

3 Anderson HR, Bailey P, West S. Trends in the hospital care of acute childhood asthma 1970-8: a regional study. $\mathrm{Br} \mathrm{Med} \mathrm{J}$ 1980;218:1191-4.

${ }^{4}$ Mitchell EA, Cutler DR. Paediatric admission to Auckland Hospital for asthma from 1970-1980. NZ Med J 1984;97:67-70.

${ }^{5}$ Mitchell EA, Elliott RB. Hospital admissions for asthma in children: a prospective study. NZ Med J 1981;94:331-3.

6 Speight ANP, Lee DA, Hey EN. Underdiagnosis and undertreatment of asthma in childhood. Br Med $J$ 1983;286:1253-6.

${ }^{7}$ Palm CR, Murcek MA, Roberts TR, Mansmann HC, Fireman $P$. A review of asthma admissions and deaths at Children's Hospital of Pittsburgh from 1935 to 1968. J Allergy 1970; 46:257-69.
${ }^{\rtimes}$ Conway SP, Littlewood JM. Admission to hospital with asthma. Arch Dis Child 1985;60:636-9.

${ }^{9}$ Fireman P, Friday GA, Gira C, Vierthaler WA, Michaels L. Teaching self-management skills to asthmatic children and their parents in an ambulatory care setting. Pediatrics 1981;63:341-8.

10 Gibson HB, Silverstone H, Ganderia B, Hall GJL. Respiratory disorders in seven year old children in Tasmania. Aims, methods and administration of the survey. Med J Aust 1969;2: 201-5.

11 Ferris BG. Epidemiology standardisation project (American Thoracic Society): recommended respiratory disease questionnaires for use with adults and children in epidemiological research. Am Rev Respir Dis 1978;118:7-51.

12 Blanc ADG. So you have asthma! Springfield, Illinois: C C Thomas, 1966:181-94.

13 Stanhope JM, Rees RO, Mangan AJ. Asthma and wheeze in New Zealand adolescents. NZ Med J 1979;90:279-82.

${ }^{14}$ Mitchell EA. Increasing prevalence of asthma in children. $N Z$ Med J 1983;96:463-4.

15 Sears MR, Rea HH, Beaglehole R, et al. Asthma mortality in New Zealand: a two year national study. NZ Med $J$ 1985;98: 271-5.

16 Anderson HR, Bailey PA, Cooper JS, Palmer JC, West S. Morbidity and school absence caused by asthma and wheezing illness. Arch Dis Child 1983;58:777-84.

17 Anderson HR, Bailey PA, Cooper JS, Palmer JC, West S. Medical care of asthma and wheezing illness in children: a community survey. J Epidemiol Community Health 1983; 37:180-6.

18 Peckman C, Butler N. A national study of asthma in childhood. J Epidemiol Community Health 1978;32:79-85.

19 Chief Health Statistician. Haspital and selected morbidity data 1983. Auckland: NHSC, Department of Health, 1984.

20 Forwell MA, Grant IW. The effect of a self-referral scheme on the pattern of hospital admissions for acute asthma. Scott Med J 1985;30:15-8.

21 Reinken J, McLeod JW, Murphy TID. Health and equity. Wellington: Department of Health, 1985. (Department of Health Special Report Series No 72).

${ }^{22}$ Hindi-Alexander MC, Cropp GJA. Evaluation of a family asthma programme. J Allergy Clin Immunol 1984;74:505-10

${ }^{23}$ Lewis CE, Rachelefsky G, Lewis MA, de la Sota A, Kaplan M. A randomised trial of A.C.T. (Asthma Care Training) for kids. Pediatrics 1984;74:478-86.

Correspondence to Dr E A Mitchell, Department of Health, South Auckland Health District, Private Bag, Manukau City, Auckland, New Zealand.

Received 4 August 1986 